\title{
Representação e ação dos operadores do sistema penal no Rio de Janeiro
}

JORGE DA SILVA

RESUMO: Não se compreende como os meios de comunicação (e mesmo acadêmicos) consigam falar e escrever sobre a violência do Rio de Janeiro e suas favelas sem aludir à desproporcional visibilidade dos negros como agentes ou vítimas. $O$ artigo sustenta que o racismo desempenha importante papel no processo e que, talvez devido à representação corrente de que o Brasil é uma democracia racial, os agentes públicos podem discriminar pessoas negras sem sequer suspeitarem de que o fazem. A análise é baseada nas diferentes visões do problema como percebido por pessoas da "classe média", de um lado, e por pessoas "pobres" de outro, e também em casos concretos de racismo levados ao sistema penal. No que tange às estratégias de intervenção policial, parece claro que em razão da hierarquização social característica de nossa sociedade, qualquer ação há que ir além do círculo vicioso das medidas organizativas como se costuma acreditar seja a solução, e corresponder a necessidades de natureza diversa. Como ponto de partida a concepção militarista do papel da polícia que perpassa a área de segurança pública no Brasil, em prejuízo da maioria da população, máxima dos mercados pela cor da pele (o foco é o Rio de Janeiro). Inadiável a incorporação à prática do setor, como questões centrais de temas como "polícia democrática", "polícia comunitária", "discriminação", etc.

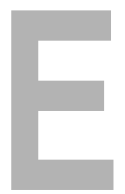

Até bem pouco tempo um tanto negligenciados pelos estudiosos das ciências sociais brasileiros, segurança pública e polícia eram temas tratados quase que exclusivamente sob a ótica jurídica, notadamente por criminalistas, e sob a ótica militar, sobretudo por militares do Exército, numa perspectiva coerentemente normativa e fragmentada. Assim, o problema acabava circunscrito, de um lado, a saber
UNITERIMS:

polícia, racismo, violência, segurança pública, direitos humanos.

Professor da Faculdade de Formação de Professores-UERJ 
SILVA, Jorge da. Representação e ação dos operadores do sistema penal no Rio de Janeiro. Tempo Social; Rev. Sociol. USP, S. Paulo, 9(1): 95-114, maio de 1997.

A expressão sistema penal é usada no presente artigo como sinônimo de sistema de justiça criminal, referindo-se ao sistema operado por um conjunto específico de agentes públicos (e eventualmente privados, como no caso dos advogados), incluindo juízes criminais, promotores públicos, defensores públicos, advogados criminais, delegados de polícia, autoridades carcerárias, autoridades da polícia e policiais em geral, e englobando a legislação penal.

$2 \mathrm{O}$ conceito de prevenção especial coincide com o de prevenção terciária, focada no condenado, diferentemente da prevenção primária (prevenção geral), orientada às causas, e da prevenção secundária, orientada aos efeitos, com programas de prevenção policial, de auto-proteção etc. (cf. Molina, 1992, p. 252254).

Cf. Gleisal (1974). Conceituando ordem pública, esse autor insiste em distinguir o seu sentido amplo do seu sentido estrito, quando ordem pública é tida como ausência de desordem, referida a manifestações públicas, distúrbios etc., como é comum entender-se ordem pública no Brasil. como lidar com o criminoso, e de outro, a saber o que fazer para "combater" o crime, prevalecendo aquilo que Da Matta (1993, p. 178) chama de "discurso teórico erudito", "normativo, jurisdicista, formalista e/ou disciplinador." Com foco no criminoso, ganham prestígio entre nós as teorias penais européias, preocupadas em explicar o comportamento "anormal" ou patológico, desde o positivismo criminológico de Cesare Lombroso e sua "criminalidade inata", passando pelas teorias racistas da "criminalidade atávica" das raças ditas "inferiores", e chegando até às teorias que pretendem explicar o comportamento individual como consequiência da pobreza, da marginalização social etc. Aqui, partir-se-á da premissa de que o sistema penal ${ }^{1}$, não obstante sua função inerentemente repressiva, "prevenirá" o crime (prevenção especial, na terminologia jurídico-penal) se cuidar que o criminoso não volte a delinqüir e segregando do convívio social os tidos por irrecuperáveis²

Com foco no "combate" ao crime, no atacado, ganham prestígio as teorias que vêem a sociedade como resultado de um consenso, no qual o crime seria uma patologia intolerável, a ser extirpada com a força do Estado, legitimado a usá-la monopolisticamente, como explicou Max Weber (1991, p. 128). Aqui, partir-se-á da premissa de que a ordem e a tranqüilidade públicas serão a resultante da "vitória" da polícia na "guerra" contra os "inimigos" do consenso, ou seja, os que insistirem em dedicar-se ao crime. A segurança pública será um problema de segurança nacional.

Com a segmentação implicada nessas duas óticas particulares, óticas muito mais profissionais do que acadêmicas, não teria sentido realmente falar do crime e da violência como fenômenos sócio-políticos, nem falar de causas e fatores que alimentam a criminalidade, nem falar de ordem pública no seu sentido amplo, abarcando, além da noção estrita de segurança, as de tranquiilidade e salubridade públicas, de ordem moral, estética, política e econômica, como demonstrou Gleisal ${ }^{3}$; nem falar da participação da sociedade civil (e do cidadão individualmente); nem falar do próprio sistema penal em geral e da polícia em particular como eventuais matrizes de violência e realimentação do crime.

Se, entretanto, segurança pública e polícia eram temas um pouco negligenciados pelos estudiosos das ciências sociais patrícios (devendo-se fazer justiça aos esforços pioneiros de alguns aplicados estudiosos, dentre os quais podemos destacar Antônio Luiz Paixão, na UFMG, Roberto Kant de Lima, na UFF, Marcos Luiz Bretas, na Fundação Rui Barbosa, e os do Núcleo de Estudos da Violência, da USP, junto com Paulo Sérgio Pinheiro), duas outras questões de certa forma correlatas sempre mereceram grande atenção ao longo do tempo: a violência e o racismo. Violência, abordada em suas múltiplas manifestações, às vezes tocando lateralmente na questão da polícia e da segurança pública. Racismo, abordado ora para negar ora para afirmar a presença desse caráter em nossa cultura, mas raramente, ou quase nunca, admitindo-se associação entre racismo e violência.

Com a exacerbação da violência urbana nos últimos anos, não só 
os temas da segurança pública e da polícia passaram a merecer maior atenção dos cientistas sociais, mas igualmente questões conexas, como ordem pública, sistema penal, direitos humanos etc., constituindo-se mesmo em "problemática obrigatória" - para usar a expressão de Pierre Bourdieu (1992), atraindo a atenção de estudiosos de praticamente todas as áreas.

Se em outros países, todavia, violência urbana e racismo são questões freqüentemente analisadas uma na perspectiva da outra, falando-se mesmo em violência étnica, violência racial, genocídio etc., no Brasil, certamente em razão da representação corrente de sermos um país sem preconceito racial, não é comum que tais questões sejam abordadas dessa forma, transparecendo daí que, para os estudiosos brasileiros, não haveria relação importante entre violência e racismo entre nós, ainda quando se admite ser o racismo marca forte de nossa cultura. Assim, se nesses outros países, onde se reconhece explicitamente uma tal animosidade racial ou étnica, a luta contra a violência implica a preliminar da luta contra a discriminação racial, cá entre nós luta-se contra a violência de uma cidade como o Rio de Janeiro, atribuindo-a (a violência) a incontáveis fatores, mas abstraindo-se sempre o fator racial como potencial gerador da violência da cidade.

O presente artigo põe luz, ao contrário, no fator racial como variável na produção da violência da cidade, com a cautela de evitar magnificar a sua importância, mas sublinha a contradição entre a confortável representação (também defendida no discurso dos operadores do sistema) e a concretude de uma ação marcadamente discriminatória partida desses mesmos operadores, cumprindo esclarecer que se trata da apresentação de alguns dados preliminares de pesquisa que desenvolvo no Programa de Pós-Graduação em Antropologia e Ciência Política (PPGACP) da Universidade Federal Fluminense (UFF), com apoio da Fundação de Amparo à Pesquisa do Estado (FAPERJ) e da Prefeitura do Rio de Janeiro, com foco na relação racismoviolência.

Considero relevante mencionar, em razão do natural emocionalismo suscitado pela discussão do tema do racismo, que o que me motivou a realizar uma tal pesquisa foi não só a experiência profissional na luta contra a violência, mas também minha condição pessoal: negro nascido e criado na contra-encosta do Morro do Adeus e nas cercanias do hoje chamado "Complexo do Alemão", no subúrbio da Leopoldina, que ascendeu socialmente e que pôde observar os fenômenos da violência e das relações raciais de diferentes patamares sociais. Parto da premissa, pois, de que a neutralidade em assunto de tamanha carga emocional é implausível, seja o estudioso negro, branco, pardo ou o que for. Trata-se, portando, da visão de um estudioso negro; e a advertência tem a finalidade de estimular o interlocutor a relativizar o que lê, mas tem também o propósito de estimulá-lo a relativizar suas próprias certezas sobre a questão.

Uma objeção que se tem levantado a uma tal abordagem é que já se produziu abundante material não só sobre violência urbana quanto sobre 
racismo no Brasil, e que talvez fosse mais útil concentrar energia no exame das formas de a sociedade enfrentar realística e pragmaticamente o problema da criminalidade violenta. Só que a produção sobre violência-e-racismo, em conjunto, é ainda pequena. Com efeito, embora nas discussões sobre a violência urbana, na linha radical do "discurso teórico-erudito", as opiniões se dividam entre os que, de um lado, a atribuem a fatores tais como a pobreza, a desigualdade, a má distribuição de renda etc.; e os que, de outro, a atribuem ao desaparelhamento da polícia e do sistema penal, à falta de prisões, à leniência do poder público e da legislação penal etc; e embora se apontem as favelas cariocas e bolsões periféricos - onde a população com a marca da raça negra é predominante - como principais fontes da violência da cidade, a grande visibilidade da participação de negros na violência, como agentes ou vítimas, parece não impressionar os estudiosos. Dão a idéia de que, para eles, este seria um dado irrelevante, pois conseguem teorizar exaustivamente sobre o tema - tomando a violência do Rio de Janeiro como referência - sem aludir, sequer de leve, a este fato.

Diante, todavia, das estatísticas e de estudos sobre a posição social relativa dos portadores da marca fenotípica da raça negra, em que a sonhada democracia racial sequer aparece como mito; e também diante do resultado de pesquisas, como é o caso da realizada por Ribeiro (1995) em seu Cor e Criminalidade, na qual, estudando processos da justiça do Rio de Janeiro no período 1900-1930, demonstra o tratamento desigual para negros e brancos, o que de certa forma se confirma por pesquisas relativas ao atual momento, como a que desenvolvo, fica claro que os operadores do sistema penal e da polícia não raro tratam de forma diferenciada as pessoas consideradas brancas em relação às não-brancas.

Adiante, após algumas notas sobre violência urbana e sobre o que estou chamando de fator racial, comento algumas entrevistas exploratórias e alguns processos decorrentes de discriminação racial, aparecendo claramente a desigualdade de tratamento. Exemplo acabado da ambigüidade cultural brasileira; entre a retórica legitimadora do Estado formal, oficial (quando o Brasil é apresentado como uma sociedade democrática, pluralista e igualitária, em que o valor do indivíduo não é medido pela sua condição social, raça, cor, religião etc.) e a realidade do Estado concreto, informal ("oficioso", para usar a expressão de Lima (1994 e 1995), quando nos revelamos uma sociedade profundamente hierarquizada e preconceituosa, exatamente no marco da condição social, da raça, da cor da pele. Ao final, após breves notas conclusivas, são apresentadas algumas sugestões.

\section{Violência urbana}

Violência, aqui, será a violência física associada à criminalidade urbana e pública; violência caracterizada muito mais pelo "discurso popular", "do senso comum", do que pelo "discurso erudito", conforme a distinção de 
Da Matta, citado acima. Além disto, sem descartar a importância de outros tipos de violência, excluem-se da apreciação: a violência ligada a saques, quebra-quebras, distúrbios civis etc.; a violência não-física (psicológica, econômica, do poder etc.); a violência no campo; e a violência doméstica e privada (contra a mulher, crianças e pessoas do círculo privado).

Ninguém discorda de que um dos grandes desafios com os quais se defronta a sociedade brasileira de hoje é saber o que fazer para conter a escalada da violência e, conseqüentemente, reduzir a insegurança e o medo. No caso particular do Rio de Janeiro (como no caso de São Paulo), o temor tem sido tamanho que não se terá como necessário ficar à mercê das manipulações estatísticas, pois os assaltos, homicídios traficantes, seqüestros, balas perdidas são uma ameaça sentida.

Independentemente de números (de a insegurança ser objetiva ou subjetiva), emoção e paixão à flor da pele, parece haver consenso em que a solução para a questão da violência urbana implica a adoção de quaisquer meios, "já, aqui e agora". Para essa solução ad hoc, tem-se em mente um dos principais motivos da existência do Estado nacional: garantir que os indivíduos vivam em segurança, protegidos da violência potencial daquele estado de natureza imaginário de que nos falam Hobbes e Locke, quando não há limites aos apetites humanos, a não ser a própria força dos indivíduos. Ou seja, da forma como explicou Max Weber, correspondendo ao princípio da "legitimidade racional-legal", dependente do monopólio do uso da força/ violência legítima por parte do Estado. Que o Estado vá às últimas conseqüências!...

Ora, que os cidadãos se comportem dessa forma emocional e apaixonada (e, do ponto de vista metodológico, irracional), é perfeitamente normal, mas o que dizer quando os representantes do Estado também agem emocionalmente, confundindo o papel de cidadão (e como cidadão, pertencente a grupos de interesse e de classe) com o de autoridade, necessariamente racional e plural?

Ocorre que na sociedade contemporânea, o uso da força/violência legítima, por si só, tem-se revelado meio insuficiente e ineficaz para conter a violência urbana (isto, é claro, numa sociedade democrática, não sendo o argumento válido para regimes totalitários, de esquerda ou de direita...). Não estamos mais na época dos salteadores de estrada e dos malfeitores das florestas dos tempos de Weber, mas ainda há aqueles que entendem que este é $o$ meio (e não um dos meios) para conter a violência “ilegítima”, num raciocínio mais ou menos assim: "O Estado tem a obrigação de garantir a integridade física dos cidadãos. Há maus cidadãos (cidadãos!...) que usam a violência para ferir, humilhar, roubar, matar, seqüestrar outros cidadãos. O Estado intervém com violência legítima - e supostamente com potencial de eficácia superior ao dos indivíduos violentos - para garantir a segurança geral. Se a segurança não é alcançada, permanecendo os indivíduos violentos, os criminosos, a praticar a violência contra os cidadãos de bem, terá sido porque o 
Estado usou violência insuficiente. Será necessário usar mais violência legítima. Se, novamente, a segurança não é conseguida, é preciso usar mais violência legítima ainda. Se, novamente, tendo usado mais violência legítima, a segurança não é obtida...".

É este raciocínio - somado ao sentimento de vingança - que as faz acreditar na eficácia dos extermínios e aplaudir os exterminadores (apenas nas conversas informais, é evidente, pois a retórica formal e pública é sempre diferente). É este raciocínio que leva cidadãos a invocarem o Estado-Leviatã de Hobbes, e verem como algo banal as Forças Armadas (Exército, Marinha e Aeronáutica) circulando pelas ruas e favelas com tanques, canhões e helicópteros de guerra a procura de bandidos urbanos; apontando tanques e canhões para favelas.

\section{Fator racial}

Cumpre alertar ainda uma vez que não se está pretendendo, de modo algum, discutir causas remotas, estruturais, nem se está tentando estabelecer nexo causal entre a questão social e a violência urbana. Porém, não se deve perder de vista a peculiar formação do País, com uma economia dependente, em termos absolutos e durante séculos, das hordas de escravos negros (como aconteceu exemplarmente no Rio de Janeiro), em proveito de uma dúzia de senhores e burocratas. Muito mais útil, nada obstante, será tentar discernir fatores do presente que vêm contribuindo para o incremento da violência. Com efeito, o próprio Estado poderá aparecer (concretamente, e não em termos abstratos) como um privilegiado perpetrador da violência que pretende combater, como alguns criminólogos têm assinalado, na trilha de Manuel Lopez-Rey (1975). Entrementes, poder-se-á impugnar este argumento, caracterizando-se a idéia de adotar uma tal metodologia como perda de tempo. E aí, ainda uma vez, o Estado formal será apresentado por seus incondicionais defensores como auto-suficiente para resolver o problema. Bastará "vontade política" para fazer cumprir o que está escrito. Assim, confundindo o enunciado formal de Estado com o Estado real, não conseguem compreender como possam existir tanta violência, corrupção, roubo, desordem, impunidade, baderna, desagregação, miséria. E aí, sonhadores, sucumbem a uma segunda tentação: a de pensar o Brasil com um referencial calcado nos aspectos positivos (apenas os positivos), encontrados em países do primeiro mundo, fazendo mau uso da teoria do tipo ideal de Max Weber. Ora, de quem será a culpa de o Brasil não ter prisões como as da Alemanha? E os Bobs londrinos, que sequer usam armas? E a integração comunitária da polícia com o povo no Japão? E a ação rápida da polícia em Nova Iorque? Aí, sonha-se com um Rio de Janeiro expurgado de todas as suas mazelas: sem favelas, traficantes de drogas, miséria, assaltantes, mendigos, pivetes, "flanelinhas", camelôs, lixo, valas "negras" etc. Não se fale mais de "donos de favela", de "seqüestros", de "balas perdidas", que isto seria ruim para a imagem do Rio de Janeiro. Que se 
SILVA, Jorge da. Representação e ação dos operadores do sistema penal no Rio de Janeiro. Tempo Social; Rev. Sociol. USP, S. Paulo, 9(1): 95-114, maio de 1997.

esconda tudo debaixo do tapete, para que se possa apresentar um Rio de Janeiro ideal: a conjugação de sua exuberante beleza natural com o que há de melhor em Berlim, Londres, Tóquio, São Francisco. Insistentemente, esta é a representação que se quer passar do Rio de Janeiro para o exterior, a despeito da realidade. Como se Nova Iorque, para ser uma das maiores cidades turísticas do mundo, e apesar de toda ação discriminatória da polícia contra minorias (negros, latinos, imigrantes e pobres em geral), tivesse conseguido se livrar das suas mazelas e fosse, hoje, uma ilha de sonhos e tranquiilidade.

Assim, com dois modelos de Estado em mente: o ideal (o paraíso) e o formal (o oficial), e confundindo este último com o Estado real (o oficioso), os renitentes defensores do Estado formal (e conseqüentemente do status quo), concluem que será preciso tornar as leis desse Estado oficial mais rígidas e alterar a estrutura das instituições voltadas para a luta contra a criminalidade e a violência. É como se esses renitentes tivessem sido possuídos pelo instinto do avestruz, com a cabeça enterrada na areia, impossibilitados ou temerosos de ver a realidade, como se imagina acontecer com essa ave.

Ampliando-se o foco, aprofundando-se um pouco mais o corte e levantando-se a cabeça, talvez seja possível identificar componentes do Estado real. Por exemplo, cite-se o dado concreto de que a criminalidade violenta tem como protagonistas destacados - seja como criminosos seja como vítimas pessoas negras e pobres dos bolsões marginalizados socialmente. Diante deste fato, corroborado pelas estatísticas, não se pode compreender como as elites do poder em geral, autoridades, políticos, jornalistas e grande número de estudiosos consigam discutir a violência do Rio de Janeiro (e como discutem!) e propor soluções para contê-la sem mencionar este fato. Será que, sendo tabu, o assunto há de ser abstraído pelo instinto do avestruz?

Diante, destarte, do que acontece numa cidade como o Rio de Janeiro, não parece impertinente, ao menos, levantar a hipótese de que o racismo seja um dos fatores da violência. Ainda que não se queira levar em consideração a hipótese, é simplificação injustificável tentar diluir a questão racial na questão social. Ou, pior ainda, que para dar suporte a esses argumentos, os seus defensores se valham de algum compêndio produzido no "primeiro mundo", do tipo "Como Combater a Violência Urbana”, escrito por, digamos, um italiano, um inglês, um francês, um canadense ou um norte-americano, para "resolver" a violência de nossas grandes cidades. Ora, esse tipo de abordagem descarta um dado aparentemente óbvio: o Rio de Janeiro é uma cidade do Brasil, país da América Latina, colonizado pelos portugueses, vizinho de países colonizados pelos espanhóis, sem contar as incursões, algumas bem sucedidas, de ingleses, franceses e holandeses pela Região, sendo característica histórica dos países da América Latina o controle da sociedade por parte da minoria branca, originária de ou identificada com os colonizadores europeus, em detrimento da grande maioria, não-branca, do povo. Mais: o fato de não se estar falando, com referência à pobreza, de uma minoria não pertencente à classe média ou alta (nesses países centrais, a classe média, em termos relati- 
vos, é constituída por largas parcelas da população, como é sabido), e sim estar-se falando da maioria do povo, ainda lutando por direitos de primeira geração: por igualdade e respeito. Lutando por habitação condigna, água, saneamento básico, higiene... E talvez fosse de grande utilidade indagar: onde estão e o que fazem, hoje, as populações constituídas pelos filhos, netos, bisnetos dos negros escravos, libertos, africanos livres, ingênuos, crioulos, mulatos e mestiços que, de acordo com o senso de 1872, constituíam quase dois terços da população brasileira? Ora, nada parecido com Itália, Inglaterra, França ou mesmo os Estados Unidos. Neste último país, por exemplo, os chamados afro-americanos, ou seja, o somatório de pretos, pardos, mulatos e mestiços de negro em geral são uma minoria que não chega a $15 \%$ da população total, diferentemente do Brasil, que, mesmo pelas viciadas estatísticas do IBGE, é apresentado como tendo 55,3\% de brancos, 4,9\% (sic) de pretos e 39,3\% de pardos, como nos dá conta o Anuário Estatístico do Brasil-1992 (IBGE, 1993, p. 161), embora todos conheçamos o problema da identidade racial no Brasil, acarretando que entre os "brancos" se incluam "pardos" de pele clara...

\section{Cidadania em face do sistema penal}

Como é sabido, o exercício da cidadania pode dar-se em torno de direitos de diferentes gerações: direitos civis, relacionados com a liberdade individual, a igualdade e a integridade física; direitos sociais, relacionados à saúde, habitação, educação, saneamento; direitos políticos, relacionados com a participação no poder político; e direitos relacionados com o lazer, o bem estar etc., interessando-nos aqui os direitos de primeira geração, os direitos civis, já que o sistema penal seria, teoricamente, o instrumento público de garantia desses direitos.

No Brasil, não se pode afirmar, diferentemente do que se pode fazer, por exemplo, com relação a Inglaterra, França e Estados Unidos (países onde floresceram e se sedimentaram os cânones dos direitos humanos), que a cidadania represente propriamente uma conquista universal do povo. Muito mais, representa o resultado de uma "regulação", em proveito daqueles que, por lei e diferenciadamente, seriam reconhecidos como desempenhando ocupações "reconhecidas e definidas em lei", como se depreende da análise de Santos (1987, p. 64-72), ao comentar a política econômico-social republicana. Não se é cidadão pelo simples fato de pertencer à comunidade. Em suma, por extensão da explicação de Santos, pode-se dizer que, para ser cidadão, há que ser trabalhador, nos termos da legislação trabalhista; ou melhor, há que

${ }^{4} \mathrm{O}$ inquérito não é específico sobre a questão racial, que só é abordada lateralmente. A pergunta principal é a seguinte: "Você / o (a) senhor (a) confia na justiça, nas leis?" ser "alguém".

Com base em depoimentos de alguns informantes ouvidos exploratoriamente ${ }^{4}$ e na análise de casos concretos de discriminação racial levados à justiça, inclino-me a concluir, como procuro demonstrar abaixo, que, no caso dos negros, o Estado oficioso dispõe de regras implícitas altamente eficientes, já que escudadas na representação da igualdade racial, capazes de 
diminuir-lhes ainda mais uma cidadania já tão diminuta.

No que concerne às entrevistas, no geral, os informantes considerados de classe média no inquérito (renda média ou alta, instrução superior, moradores de áreas nobres da cidade) admitem que a justiça não funciona igualitariamente, favorecendo muito mais a quem tem dinheiro e poder. Reconhecem a presença do racismo entre nós, e que a polícia “às vezes" discrimina "pessoas de cor"; mas não acham que aqui (a comparação é sempre com os Estados Unidos) isto seja realmente um problema. Insistem em que pode haver "discriminação social", e não racial, quase sempre escudando o argumento na miscigenação, na "mistura". Quanto à violência, atribuem-na muito mais a leis brandas (acham que deveriam ser mais duras) e ao despreparo da polícia do que a outros fatores. Os dois excertos abaixo são exemplares:

Acho que não tem nada a ver uma coisa com a outra.

Será que tem? Eu também sou pobre; meu pai era muito pobre... e eu não dei pra bandido. Eu acho que não tem nada a ver. É que essa gente parece que já tem o instinto... sei lá.

Outro informante:

É que os bandidos estão mais nesses lugares. Eu acho que tem a discriminação social, nada dessa história de racismo. Às vezes a polícia escolhe pela aparência, mas não é sempre [...] O problema é essa história de direitos humanos. Direitos humanos pra bandido?Eu acho isso errado.

Já os informantes considerados pobres (baixa renda, pouca ou nenhuma instrução formal, moradores de favelas e da periferia) têm uma percepção um pouco diferente. Acreditam que são alvos preferenciais do sistema, particularmente da polícia, em função da sua condição social e racial (social, se aceitarmos que nas camadas de baixa renda do Rio de Janeiro, as pessoas com pele não tanto escura sejam tidas por brancas e se apresentem como tal). Dentre esses informantes, os assumidamente negros são os mais categóricos em afirmar que são discriminados em função da cor da pele. A polícia é quase sempre considerada inimiga ("alemão", como referem alguns informantes). Impressionou-me sobremaneira a afirmação de um informante, um rapaz favelado, negro, de dezoito anos de idade, entrevistado no seu local de trabalho, onde é ajudante de pedreiro, referindo-se a um conhecido da favela que entrara para a polícia (o que pode dar bem a idéia de como a polícia é vista em algumas comunidades, já que não se trata da visão de um bandido): "Pô! O cara é traidor! Entrar pra polícia?" E um outro informante:

A justiça pode partir da polícia, do governo... Para o povo a justiça é a polícia. Pode existir lei, mas eles é que fazem a lei. Eu acho errado essa lei que o PM já chega batendo em vez de pedir documento. Eles chegam atirando. Pra eles, irmão de bandido é 
bandido, mãe de bandido é bandido.

Chama a atenção igualmente a utilização freqüente da palavra "eles" para indicar, genericamente, os que estariam em oposição aos interesses dessas camadas baixas. Sem que esse "eles" em nenhum momento seja especificado, podendo-se concluir que são os que detêm poder, dinheiro, políticos, policiais etc. Mais que tudo, revoltam-se com os privilégios penais, como assinala este informante, que tem um irmão preso, condenado por roubo: As leis são justas mas não são cumpridas. Por exemplo, no caso aí do PC Farias. Tem (sic) dinheiro, fica preso dentro de casa... Esses bicheiros do jogo do bicho ficam com mordomia, telefone celular, TV a (sic) cores; diferente dos outros. Enquanto os outros são igual a bicho (sic), tudo enjaulado em cima do outro. Tem (sic) presídio que nem banho de sol os 'bichos' podem tomar. O meu irmão perdeu a mão; os médicos deixaram dar gangrena. Podiam ter evitado, mas como é pobre...

De fato, talvez esta questão dos privilégios penais, favorecendo com "foro privilegiado" ou "prisão especial" quem tenha curso superior, comerciantes, parlamentares, militares, religiosos etc. (acabando por favorecer bicheiros, ladrões e criminosos de todo gênero), devesse merecer maior atenção dos cientistas sociais, para se saber se acarretam ou não consequiências deletérias na segurança pública e na produção da violência.

Outro ponto importante. Nas comunidades de baixa renda, as pessoas não parecem muito preocupadas com o sistema oficial de leis e justiça, que lhes parece inerentemente opressor e discriminatório. Preocupa-lhes, sim, como as coisas funcionam no seu dia-a-dia, sendo fundamental agir de acordo com as normas de suas comunidades, ainda que estas estejam em conflito com as normas oficiais do Estado. E seguem à risca as "leis" do lugar (é assim que costumam referir-se às ordens dos traficantes: "É lei deles â̂").

Quanto aos casos concretos de discriminação racial levados à justiça, comentam-se abaixo algumas racionalizações encontradas em processos formais de racismo levados ao sistema penal, em que se evidencia o divórcio entre a representação cordial com a qual o "mundo jurídico" opera e a prática intolerante dos seus operadores em relação aos fatos que contrariem a representação, em detrimento da cidadania dos negros, conforme já comentei em maior profundidade alhures (cf. Silva, 1994, p. 157-172).

\section{- Primeiro caso:}

Apelação Criminal. Um cidadão havia sido condenado pela prática de preconceito racial (art. $4^{\circ}$ da Lei 1.390, de 03-07-51, Lei Afonso Arinos), em processo decorrente de flagrante delito, por ter impedido que outro cidadão, negro, entrasse em local de exame de motorista, onde o ofendido atuava na condição de instrutor de auto-escola, e o acusado, na de coordenador dos 
exames.

Na audiência de instrução e julgamento, nas alegações finais, o promotor, o pólo da acusação, resolve defender o acusado:

$O$ acusado não teria a intenção de ofender a vítima e que assim deve ser absolvido, também diante das dúvidas do seu espírito a respeito do fato, chamando a sua atenção para adotar outra conduta no trato com as pessoas, sabido que todos têm direito à sua dignidade.

\section{- Outro caso: Ocorrência: VPI ${ }^{1}$}

Antes de tudo, será importante esclarecer o que significa a sigla VPI, o que, por si só, se constitui num dado importante da análise. Na realidade, trata-se de um "procedimento" da Polícia Civil do Rio de Janeiro, como tantos outros criados em diferentes Estados da Federação com o pretexto de "racionalizar" o serviço, mas que apresentam a característica de possibilitar que fatos criminais levados formalmente à polícia esgotem-se no âmbito da delegacia, pois, se instaurado, o inquérito não pode ser arquivado pela polícia.

No presente caso, ocorrido num salão de beleza de um condomínio de classe média do Rio de Janeiro, uma mulher que havia marcado hora com a manicura, ao chegar a sua vez (já estava sentada na cadeira), foi chamada à porta do salão e convidada a se retirar pela própria manicura que havia marcado o horário, a qual lhe explicou que "não podiam atender domésticas, muito menos num sábado". (Obs.: A doméstica convidada a se retirar era negra).

Formalizada a queixa conforme o figurino, com a ajuda da patroa da doméstica, eis que o delegado, em lacônico despacho, manda registrar a ocorrência e instaurar uma VP I ( sic), da qual fica encarregado um detetive de polícia. Este, "delegado" do delegado, toma por termo, "Termo de Entrevista" (outra invenção), as declarações da doméstica, da patroa desta, da proprietária do salão e da manicura, e no final "sentencia", igualmente de forma lacônica, que a "Verificação" deveria ser "suspensa" (outra invenção):

tudo não passou de um mau (sic) entendido entre as partes, visto a notificante já ter freqüentado o local anteriormente e em face de horários e normas do estabelecimento.

E o delegado encerra o assunto de forma fulminante: "Suspendamse as investigações”.

\section{- Outro caso: Processo criminal.}

Zona sul do Rio de Janeiro. No calçadão em frente à praia, dois policiais-militares suspeitam da atitude de um homem e o abordam, procedendo à busca pessoal no mesmo, nada encontrando que o incrimine. Um circunstante, que presencia a cena, fala em voz alta que "só podia ser coisa de preto". Segundo o relato dos policiais, estes olharam para o circunstante e

\footnotetext{
1 Verificação de procedência de informações.
} 
notaram que aquelas palavras eram dirigidas a ambos. Indagaram do referido cidadão o porquê daquelas palavras e pediram-lhe que se identificasse, o que foi recusado, tendo o cidadão continuado a repetir a frase ofensiva, então de forma mais agressiva. Alegaram os policiais ainda que, diante da recusa do cidadão em acompanhá-los à delegacia de polícia, tiveram que usar a força, enquanto o cidadão continuava a repetir as ofensas, acrescentando que os policiais só faziam aquilo porque estavam armados, e que se fosse "na mão ficava ruim" para eles. Levaram-no para a delegacia, onde o mesmo foi autuado em flagrante.

Em juízo, dada vista ao Ministério Público, a promotora pede o arquivamento dos autos, mas o faz somente “em relação ao indiciado”, pedindo ao juiz o relaxamento da sua prisão e a imediata expedição do alvará de soltura. E se volta contra os policiais.

Requer, ainda, o Ministério Público a este juízo:

$1^{\circ}$ - Seja oficiado à D. Corregedoria de Polícia Civil, enviando cópia do flagrante e da promoção do Ministério Público, a fim de que se tomem as medidas necessárias de precaução em relação às Delegacias do Estado.

$2^{\circ}$ - Seja oficiado ao Comando em que servem os PMs, solicitando cópia da folha de assentamentos de ambos.

Após a juntada das folhas, protesta por nova vista.

Dado interessante é que a promotora de justiça chega a recorrer à célebre expressão latina: Nullum crimen, nulla poena sine lege ("não há crime sem lei anterior que o defina nem pena sem prévia cominação legal"), para dizer que o crime de racismo estava previsto na Constituição, mas que ainda não havia sido promulgada a lei decorrente. Vejam só. A promotora escreveu isto em 26 de novembro de 1989, ou seja, mais de dez meses depois da vigência da Lei 7.716, retro-referenciada. Parece ficção, mas é a pura realidade. Curiosamente, no ofício enviado à Polícia Civil pelo juiz lê-se:

Solicito de V. Sa as medidas necessárias de precaução junto a todas as delegacias do Estado, com a finalidade de que, doravante, fatos como o do flagrante $X$, oriundo da X DP, tendo como indiciado $X$, sejam evitados.

Tal recomendação, que foi cumprida pelos escalões administrativos da Polícia Civil, como informou ao juízo o Corregedor, constitui-se numa temeridade. Embora ambígua do ponto de vista formal, a recomendação do juiz será interpretada pelos policiais de "todas as Delegacias de Polícia do Estado" como uma sinalização para que não formalizem qualquer caso de "preconceito de raça ou de cor". Mais vale a representação de um país sem esse problema, não importando a dignidade humana dos cidadãos discriminados. E ai de quem recorrer ao sistema na "contramão" dessa representação... 
SILVA, Jorge da. Representação e ação dos operadores do sistema penal no Rio de Janeiro. Tempo Social; Rev. Sociol. USP, S. Paulo, 9(1): 95-114, maio de 1997.

\section{- E outro caso: Processo: Notificação Judicial}

Um jornal de grande circulação no Rio de Janeiro publica, em coluna assinada, matéria ilustrada com foto, em que se vêem o governador do Estado e várias autoridades militares, sobretudo oficiais superiores da Polícia Militar, assistindo a uma formatura solene na Escola de Formação de Oficiais. Como o assunto central da coluna era corrupção mais precisamente, malversação do dinheiro público, o colunista resolveu criar uma legenda estilizada para a foto, a qual dizia: "ESSE NEGÃO AÍ ATRÁS TÁ METENDO A MÃO NO TEU BOLSO, MOREIRA! GRAVA ELE, GRAVA!"

O "negão" apontado na legenda era um coronel da Polícia Militar, negro, solenemente fardado como os demais militares presentes, todos brancos (ou não-negros...).

Com base na Lei ${ }^{\circ}$ 5.250, de 09 de fevereiro de 1967 (Liberdade de Manifestação do Pensamento e da Informação), os advogados requereram a "notificação judicial" do editor do jornal, bem como do responsável pela coluna, para que fossem dadas as explicações nos termos da Lei (em 48 horas), e bem assim requereram o "direito de resposta" do ofendido.

A juíza recebe o requerimento e determina a notificação dos responsáveis, nos termos requeridos pelo ofendido. Isto em 2 de junho de 1989. No dia 16 de junho, o oficial de justiça “certifica” ao juiz que compareceu ao jornal e foi "informado pelo funcionário responsável" que o editor não compareceria naquela semana, e que o articulista encontrava-se "viajando, não conhecendo a data do seu retorno".

No dia 10 de julho, depois que o oficial de justiça novamente "certifica" ao juiz que não conseguiu entregar a notificação, o juiz (era outro) despacha: "Diga o notificante". Ou seja, ao invés de adotar providências contra os indiciados (ou contra o oficial de justiça...), o juiz manda os autos aos advogados do coronel, sem dizer para quê.

E continuam as delongas e mais delongas durante mais alguns meses até que, no dia 31 de maio de 1990, o notificado informa ao juiz que cumpriu a determinação judicial, juntando a coluna com o resumo das explicações, publicada no domingo anterior, dia 27 de maio de 1990 (quase um ano depois, o que deveria ser cumprido em quarenta e oito horas). Cientificado o advogado do ofendido, o juiz manda arquivar o processo em 21 de setembro de 1990. E ponto final. Quanto ao direito de resposta, que era o propósito explicitado, e reiterado, pelo ofendido...

Interessante que, se se pergunta aos operadores do sistema sobre esses fatos, na melhor das hipóteses admitem que pode haver uma ou outra exceção à regra da imparcialidade. Os policiais chegam a manifestar indignação quando se os acusa de selecionar "suspeitos" com base na cor da pele, o que não precisava ser evidenciado no inquérito, pois é fato notório, nada nos autorizando, contudo, a concluir que não estejam sendo sinceros. Com certeza, praticam a discriminação sem se darem conta de que o fazem. A força da representação obnubilando e confundindo-se com a realidade. 


\section{Conclusão}

Esses dados preliminares estão a indicar que o fator discriminação racial é um componente importante na produção da violência na cidade do Rio de Janeiro; e que a pretensão de enfrentar a violência com violência tem aumentado o fosso, tudo indicando que a negação da cidadania naquilo que esta tem de mais elementar - os direitos de primeira geração - constitui-se num elemento potencializador da violência. A utilização da força/violência como meio privilegiado parte do engano primordial de não se reconhecer que não estamos lidando com "minorias" (na representação branca), como acontece atualmente em países europeus e nos Estados Unidos. Não; cá entre nós, tratase da grande massa da população, a quem se quer impor a ordem oficial pela força. Se se podem reconhecer as dificuldades do Estado para ampliar o desfrute dos direitos de segunda, terceira e quarta gerações por parte de maiores parcelas da população, não se compreende o empenho em direcionar o poder do Estado, seletivamente, contra os destituídos daqueles outros direitos, e muito menos ainda se pode compreender que agentes do Estado não lutem contra a discriminação, e sim, ao contrário, a pratiquem.

Definitivamente, parece que a luta contra a violência no Rio de Janeiro, independentemente do esforço do sistema penal e da polícia, há que passar pela preliminar da luta contra a discriminação (social e racial), o que implica o reforço das práticas igualitárias propostas formalmente pelo Estado em sua Constituição, fazendo com que cada indivíduo, independentemente de sua condição social, de suas relações, cor, raça, religião, gênero etc., tenha o mesmo valor humano, particularmente em face do Estado. O que está em pauta é o que o Estado e a sociedade organizada podem fazer em termos da promoção da cidadania, independentemente de recursos econômico-financeiros, pois tratar de forma igualitária os cidadãos e levar em conta a dignidade humana do mais humilde favelado não custa dinheiro. Custará apenas o empenho em desconstruir os paradigmas autoritários e preconceituosos característicos da sociedade brasileira.

É realmente desconfortável para a maioria dos brasileiros admitir que a raça desempenhe papel importante na produção da violência numa cidade como o Rio de Janeiro; porém as evidências indicam que a discriminação racial por parte de agentes do sistema penal, e não apenas por parte de policiais, é um problema que precisa ser enfrentado, especificamente. E que fique claro que não se trata de uma questão meramente humanitária, senão de sobrevivência e de tranqüilidade geral.

Como este Seminário Internacional se propôs a estudar as "estratégias de intervenção policial no Estado contemporâneo", talvez fosse relevante levar em conta, sem prejuízo dos princípios gerais que certamente emergirão da discussão, as restrições impostas pelas peculiaridades dos diferentes Estados nacionais, especialmente aquelas relacionadas com o contraste entre países desenvolvidos, de um lado, como França, Alemanha, Canadá ou Estados 
Unidos, e países em desenvolvimento, do outro, como é o caso do Brasil. Naqueles países, amplas parcelas da população pertencem às camadas médias (incluídos os aptos a prover, além das necessidades básicas de alimentação, vestuário, transporte, saúde, educação, as necessidades mínimas de lazer e bem estar), e minorias são realmente minorias quantitativas (como é o caso dos não-brancos nos Estados Unidos). Num país como o Brasil, ao contrário, pequenas parcelas da população podem ser consideradas como pertencentes à camada média, em termos sócio-econômicos, mesmo pelos padrões brasileiros, e não se pode falar em minorias raciais quando o foco é uma cidade como o Rio de Janeiro, cuja Região Metropolitana, mesmo pelas estatísticas interessadas do IBGE (as quais incluem na categoria de brancos um grande número de mulatos de pele clara...), pretos e pardos somam 43,9\%, conforme dados da PNAD(1989). Se nas grandes cidades daqueles países o problema é saber o que fazer para garantir o respeito às minorias, já que a população em geral "exige" ser respeitada, aqui o problema é fazer com que os operadores da lei e da ordem respeitem a maioria quantitativa da população, já que a elite e a minúscula classe média (predominantemente brancas) não são alvo da violência e do desrespeito por parte desses operadores. Muito ao contrário.

Com certeza, a revolta e a indignação que esse quadro desperta nas camadas discriminadas podem explicar muito da violência vivida no Rio de Janeiro. Uma espécie de "efeito bumerangue", pois as explicações lombrosianas e as teorias do atavismo criminal das raças "inferiores" (teorias superadas mas com forte presença, como se evidenciou nas entrevistas) serão insuficientes para responder por que os bandidos exibem tanta desumanidade - e mesmo animalidade, comoé comum ouvir-se-e requintes de crueldade em suas ações, nunca perdendo a oportunidade para, além de tudo, humilhar suas vítimas. Ora, mesmo sem querer simplificar a questão, o que esperar de pessoas sem perspectiva, vivendo em condições humilhantes; e que, desde crianças, viram parentes, irmãos mais velhos e vizinhos serem discriminados, humilhados, presos e mortos pela polícia, muitos dos quais inocentemente?

\section{Sugestões}

Não poderia concluir sem oferecer à análise algumas idéias e sugestões relativas especificamente ao tema do Seminário: "Estratégias de Intervenção Policial no Estado Contemporâneo", para não parecer que tentei fugir do tema central. É que, temendo tomar a instituição policial como um compartimento estanque (como não é incomum acontecer nos estudos sobre a polícia no Brasil), sempre indago se é possível, num país com as características do nosso, enfrentar o problema da polícia isoladamente, ou melhor, se é possível ter uma polícia descompassada de um sistema penal com idêntica ideologia, e de um sistema político que, concretamente, legitima suas práticas autoritárias e preconceituosas, sendo esta uma preocupação recorrente em minhas refle- 
xões, como já referi em trabalhos anteriores (cf. Silva, 1990; 1996, p. 497-519).

Com base nessa indagação primordial é que alinho as sugestões abaixo, umas de caráter específico, na esfera restrita da polícia, e outras de caráter mais genérico, embora também afetando as "estratégias de emprego da polícia numa sociedade contemporânea". São indicadas medidas que, a meu ver, independem de alteração legislativa.

a. Na esfera restrita da polícia:

1 - Incorporar os princípios da polícia comunitária-interativa, adaptando-os à realidade brasileira, como vem ocorrendo em alguns estados da Federação, notadamente no Estado do Espírito Santo, sendo exemplar o projeto desenvolvido pela Polícia Militar no Município de Guaçuí, naquele Estado, em parceria com a Prefeitura e todos os segmentos da comunidade municipal. Medida cuja implementação depende apenas de romper resistências culturais internas. Só funciona se for decisão assumida pelo governo.

2 - Modificar os currículos e, principalmente, a metodologia das academias de polícia brasileiras, colocando ênfase em assuntos que respondam às necessidades de uma sociedade livre, tais como: o papel da polícia numa sociedade democrática, prevenção e repressão policial, patrulhamento preventivo, direitos humanos, criminologia, problemas de grupos discriminados etc., estimulando a reflexão crítica, especialmente no ensino dos altos escalões. Se possível, dado o caráter aberto da atividade policial, integrar esse ensino com o ensino civil, como vem fazendo, por exemplo, a Polícia Militar do Estado da Bahia, onde o Curso Superior de Polícia (para tenentes-coronéis e majores) é ministrado na Universidade Federal da Bahia, em convênio com aquela instituição, sendo oferecidas algumas vagas para juízes, promotores, delegados, advogados etc. Medida cuja implementação encontra resistência dos policiais, aferrados a um tipo de ensino com a característica de treinamento irreflexivo e repetitivo, mas que pode ser posta em prática por decisão dos governos estaduais, concertadamente com a Universidade.

3. Modernizar a estrutura das forças policiais, adaptando-as aos modelos organizacionais do mundo competitivo atual, reduzindo os níveis de decisão, dando maior autonomia decisória aos policiais da ponta da linha como contrapartida de uma maior responsabilidade individual perante a organização e o público. Medida administrativa, pode ser implementada por decisão dos próprios dirigentes da polícia.

\section{b. De caráter genérico:}

1 - Enfatizar, na prática, a distinção entre problemas globais, a serem enfrentados no nível nacional, como o crime organizado, o narcotráfico e o contrabando de armas, e problemas locais, que podem ser enfrentados inicialmente pelo município, com o fortalecimento das guardas municipais, a exemplo do Rio de Janeiro e São Paulo, notadamente no Rio de Janeiro, onde a Guarda Municipal vem assumindo, com grande eficiência, funções de in- 
teresse do dia-a-dia da população, como o trânsito, o cumprimento das posturas municipais, o policiamento de parques, jardins e outros espaços municipais, liberando a Polícia Militar para tarefas de interesse mais geral da população do Estado, como a luta contra a criminalidade e a violência, grandes eventos, controle de distúrbios civis etc. Não se pode compreender a disposição da União Federal para atuar com as Forças Armadas e a Polícia Federal nos limites urbanos contra bandidos locais, como aconteceu no Rio de Janeiro em 1994/95 quando da chamada Operação-Rio, e se alegue que os efetivos da Polícia Federal são insuficientes para impedir a entrada das toneladas de drogas que são consumidas no Brasil e das toneladas de armas de guerra e munição consumidas pelos traficantes; e se alegue da mesma sorte que não compete às Forças Armadas executar funções de polícia nas fronteiras, nas nossas costas e portos, e nem nos nossos aeroportos (inclusive os clandestinos) para igualmente impedir a entrada de armas e drogas. Medida complicada, dependendo da decisão concertada do governo federal, dos governos estaduais e dos governos municipais.

2 - Empregar a força do Estado estritamente dentro dos limites constitucionais, acionando todo o sistema penal na luta contra a criminalidade e a violência: polícia, justiça criminal, ministério público, subsistema prisional, advocacia criminal, nos níveis federal e estadual, devendo-se paralelamente repensar a forma como atuam contra a violência os operadores do sistema. Medida complicada que é dependente do empenho do governo federal e do apoio do Poder Judiciário, concertadamente com os governos estaduais, a sociedade civil e a Universidade.

3 - Desenvolver ação decisiva contra o consumo de drogas por parte da juventude. Medida que pode ser implementada a partir de: um amplo programa nacional de prevenção do consumo de drogas, de iniciativa da União e com a participação ativa dos estados, municípios, da sociedade civil e dos meios de comunicação; mudança radical da atitude permissiva da sociedade em face do consumo de drogas por parte da juventude. (Ainda que admitindo a inutilidade da criminalização do uso, será forçoso admitir que a defesa apaixonada da descriminalização oferece os elementos para a permissividade).

4 - Agir o governo federal, concertadamente com os demais países e a Sociedade civil latino-americano, desenvolvendo gestões, inclusive diplomáticas, no sentido de denunciar publicamente a facilidade com que são vendidas, pelos Estados Unidos e outros países desenvolvidos, armas pesadas para armar os traficantes dos países latino-americanos e exigir maior controle da venda dessas armas.

Não poderia finalizar sem chamar a atenção para um ponto que considero capital. Discurso erudito ou de senso comum, a verdade é que a distinção entre as categorias polícia e segurança pública acabou neutralizando-se no Brasil. Segurança pública passou a ser sinônimo de polícia. Na reuniões para discutir segurança pública, lá estarão os estudiosos a discutir polícia. Uma polícia? Duas polícias? Civil? Militar? Mais policiais? Mais 
SILVA, Jorge da. Representação e ação dos operadores do sistema penal no Rio de Janeiro. Tempo Social; Rev. Sociol. USP, S. Paulo, 9(1): 95-114, maio de 1997.

armas? Mais viaturas? Melhores salários? Melhor seleção? Daí, se se deseja propiciar maior segurança à população, resolve-se que o que se deve fazer é reformar a polícia. Incompreensível que, em face da complexidade do problema da segurança pública, em que o sistema penal como um todo tem um peso específico, se decida "reformar" apenas a polícia. Ora, parece óbvio que uma tal reforma seja necessária, mas por que a insistência em reformar só a polícia? E as demais instituições do sistema penal? Seria a polícia realmente a mais importante? Ou será que queremos, diante da falência do sistema como um todo, erigir a polícia em uma espécie de "sistema alternativo informal", enfeixando nela as funções de vigiar, prender, julgar e punir do Estado oficioso?... Ou será que esta atitude é fruto da crença na premissa de que uma polícia bem treinada, equipada, numerosa e bem paga é fator suficiente para resolver o problema da segurança pública? Talvez fosse preciso relativizar a crença nessa premissa, a qual, se fosse verdadeira, já teria transformado as metrópoles norte-americanas em verdadeiros paraísos de tranquiilidade.

Recebido para publicação em fevereiro/1997

UNITERIMS:

police,

racism, violence, law enforcement, human rights.
ABSTRACT: Ideal and reality of the criminal justice system: Rio de Janeiro, a city without racism. It is to be understood why the media (and even scholars) can manage to speak and write about the peculiar violence of Rio de Janeiro and its "favelas" (slums), making no point of the desproportionate visibility of black people as perpetrators or victims. The article claims that racism plays an important role in the process, and that, probably due to the taken-forgranted assumption that Brazil is a racial democracy, public officers may discriminate black people withou even suspecting that they are doing so. The analysis is based on the different views of the problem, as perceived by "middle class" people on the one hand and by "poor" people on the other; and also on actual cases of racism taken to the criminal justice system. Concerning the "strategies of police intervention", it seems clear, accounting for our distinctive hierarchical society, that any action should go far beyond the vicious circle of "organizational"measures, as is normally assumed to be the solution, and should respond to needs of a different nature. The starting point might be the militarist misconception of the police role that pervades law enforcement in Brazil, to the detriment of most of the Population, specially those marked by the colour of their skin (the focus being Rio de Janeiro). Themes like "police in a democracy", "community policing", "anti-discrimination" and the like might be of much help to law enforcement if put at issue with prominence. 


\section{REFERÊNCIASBIBLIOGRÁFICAS}

Bourdieu, Pierre. (1992) A economia das trocas simbólicas. São Paulo, Editora Perspectiva.

DA MatTA, Roberto. (1979) Você sabe com quem está falando? In:

Carnavais, malandros e heróis. Rio de Janeiro, Zahar, p. 139 193.

(1993) Os discursos da violência no Brasil. In: Conta de mentiroso: sete ensaios de antropologia brasileira. Rio de Janeiro, Rocco.

Gleisal, Jean Jackes. (1974) La police national. Grenoble, Presses Universitaires.

KAnT DE Lima, Roberto. (1995) A polícia da cidade do Rio de Janeiro: seus dilemas e paradoxos. $2^{\mathrm{a}}$ edição. Rio de Janeiro, Forense.

. (1994) Sincretismo jurídico ou mera esquizofrenia? A lógica judicial da excludência e a organização judiciária brasileira. Universidade Federal Fluminense (mimeo).

LoPEZ-Rey, Manuel. (1975) Criminologia. 2 vols. Madrid, Biblioteca Jurídica Aguilar.

Molina, Antonio García-Pablos de. (1992) Criminologia: uma introdução e seus fundamentos teóricos. Tradução de Luiz Flávio Gomes. São Paulo, Editora Revista dos Tribunais.

PAIXÃo, Antônio Luiz. (1985) A distribuição da segurança pública e a organização policial. In: . A Instituição Policial. Rio de Janeiro, O.A.B.

PinheIro, Paulo Sérgio. (1982) Polícia e crise política: o caso das polícias militares. In: . A Violência Brasileira. São Paulo, Brasiliense. p. 57-91.

Ribeiro, Carlos Antônio Costa. (1995) Cor e criminalidade: estudo e análise da justiça no Rio de Janeiro (1900 - 1930). Rio de Janeiro, Editora UFRJ.

SAnTos, Wanderley Guilherme dos. (1987) Cidadania e justiça: a política social na ordem brasileira. $2^{\text {a }}$ edição. Rio de Janeiro, Campus.

Silva, Jorge da. (1990) Controle da criminalidade e segurança pública. $2^{\mathrm{a}}$ edição. Rio de Janeiro, Forense.

. (1994) Direitos civis e relações raciais no Brasil. Rio de Janeiro, Luam.

. (1996) Militarização da segurança pública e a reforma da polícia: um depoimento. Ensaios jurídicos - o direito em revista, Rio de Janeiro, Instituto Brasileiro de Atualização Jurídica (IBAJ), p. 497519. 
SILVA, Jorge da. Representação e ação dos operadores do sistema penal no Rio de Janeiro. Tempo Social; Rev. Sociol. USP, S. Paulo, 9(1): 95-114, maio de 1997.

SOARES, Luiz Eduardo et alii. (1996) Violência e política no Rio de Janeiro. Rio de Janeiro, ISER/Relume Dumará.

Weber, Max. (1991) Os três tipos puros de dominação legítima. In: CoHN, Gabriel (org.). Max Weber. $5^{\mathrm{a}}$ edição. São Paulo, Ática. 